LCLS-TN-07-1

January 2007

\title{
RF Processing Experience with the GTF Prototype RF Gun*
}

\author{
J.F. Schmerge, D.H. Dowell and S.M. Gierman
}

\begin{abstract}
The SSRL Gun Test Facility (GTF) was built to develop a high brightness electron injector for the LCLS and has been operational since 1996. A total of five different metal cathodes ( $4 \mathrm{Cu}$ and $1 \mathrm{Mg}$ ) have been installed on the GTF gun. The rf processing history with the different cathodes will be presented including peak field achieved at the cathode. The LCLS gun is intended to operate at $120 \mathrm{MV} / \mathrm{m}$ and fields up to $140 \mathrm{MV} / \mathrm{m}$ have been achieved in the GTF gun. After installing a new cathode the number of rf pulses required to reach $120 \mathrm{MV} / \mathrm{m}$ is approximately 5-10 million. Total emitted dark current and Fowler Nordheim plots are also shown over the life of the cathode.
\end{abstract}

\section{Introduction}

The GTF photo-injector gun is an S-band standing-wave structure, with two resonant cavities and an intervening thick washer (Figure 1). The flat, back wall of the first cavity is a copper plate that serves as photocathode when illuminated with ultraviolet light from a pulsed, high-power laser. RF power enters the gun through an iris on the outer wall of the second cavity, and is coupled to the first through the axial opening of the washer. The first cavity is often referred to as a half cell, because its full-cell length has been truncated by the cathode plate and the second cavity is called the full cell.

The gun is designed to operate in a $\pi$ mode, with the peak field on axis in each cell approximately equal. The maximum in the half cell occurs at the cathode, and in the full cell near the center of the cavity. The field profile and tuning procedures are discussed in a separate tech note [1].

This note describes the history of rf processing the gun at the GTF with five different cathodes. Peak field and total emitted dark current are the primary measurements during rf processing. The following parameters are logged during processing:

1. Peak rf field in the gun

2. Peak dark current

3. Total integrated dark current

4. Vacuum pressure in the gun and downstream

5. Waveguide gas

6. Repetition rate

7. Solenoid current

* Work supported in part by the DOE Contract DE-AC02-76SF00515. This work was performed in support of the LCLS project at SLAC. 
8. RF pulse length

9. Incident $\mathrm{rf}$ power

10. RF drive power

11. Klystron voltage

12. RF attenuator setting

13. Date and Time
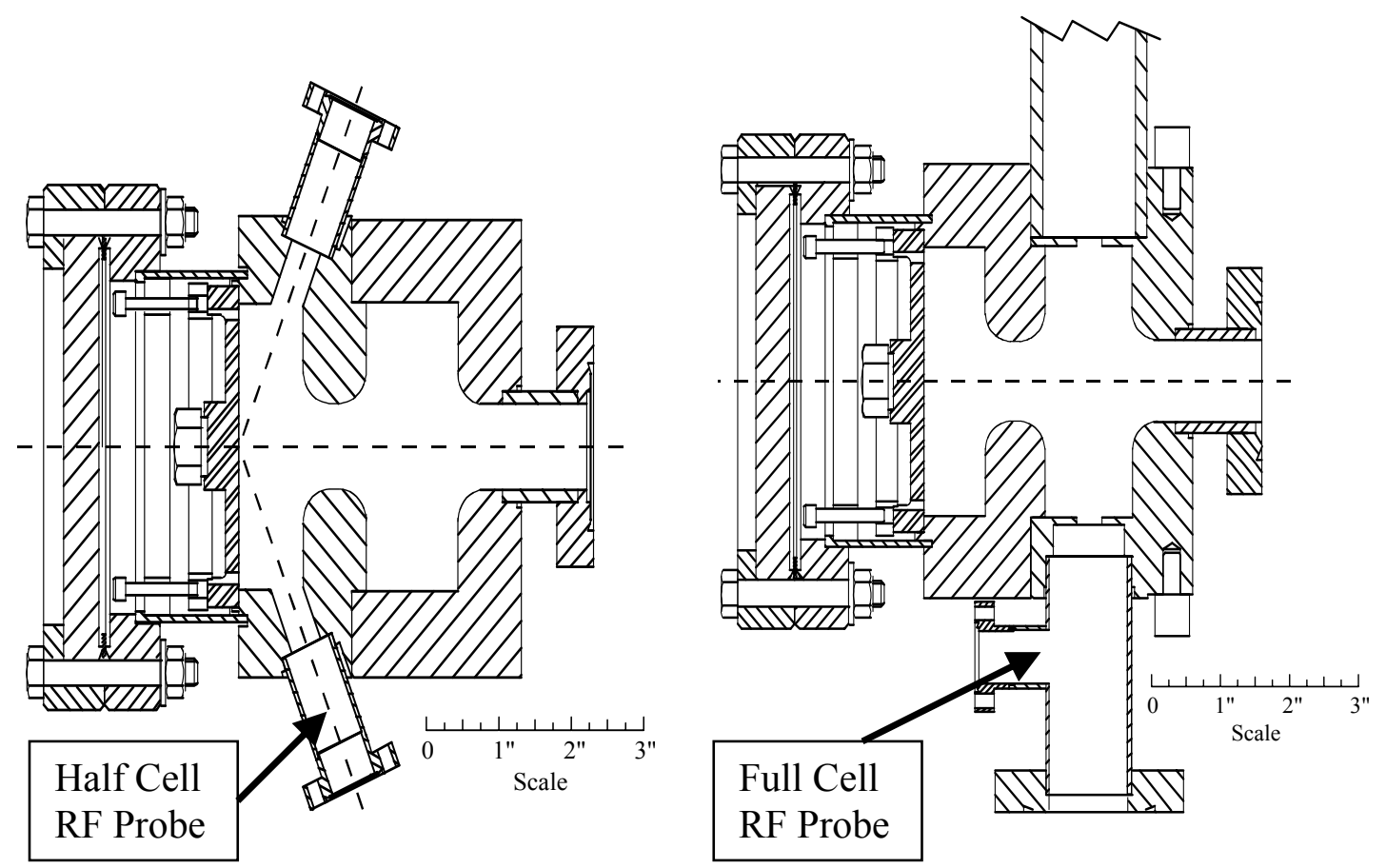

Figure 1 Two cross sections of the GTF gun, related by a 45 degree axial rotation. The beam is generated at the cathode plate on the left and exits the gun on the right. RF power is injected through the waveguide coupling hole into the full cell and couples to the half cell through the cell-to-cell iris.

We do not log the reflected rf power as it is the waveform shape that is interesting and not just a single value. Thus the reflected power waveform is recorded on occasion but the peak reflected power signal is not logged with all the other data. However, the reflected power signal shape is optimized by changing the gun temperature prior to starting rf processing.

\section{Cathodes}

A total of five cathodes have been installed on the GTF gun. Three of the five have been polycrystalline copper cathodes which require no joint since the cathode is the entire back plate. We have also installed a single crystal $\mathrm{Cu}$ and a $\mathrm{Mg}$ cathode. The diameter of the single crystal cathode plug was $1 \mathrm{~cm}$ and the magnesium plug was $2 \mathrm{~cm}$. A summary of the cathodes installed at the GTF is given in Table 1. The gun was baked prior to rf processing at approximately $200 \mathrm{C}$ for several days after each installation. 
The highest peak field of $140 \mathrm{MV} / \mathrm{m}$ was achieved with cathode \#1 although the field was not maintained for more than a few minutes. The Mg cathode produced the weakest field with a maximum field of $110 \mathrm{MV} / \mathrm{m}$. All the $\mathrm{Cu}$ cathodes exceeded $120 \mathrm{MV} / \mathrm{m}$.

Cathodes 3-5 have had extensive data collected during the rf processing procedure. Most of the results reported here have been derived from data collected during processing these three cathodes.

Table 1 Summary of cathodes installed at the GTF.

\begin{tabular}{|l|l|l|l|l|l|}
\hline $\begin{array}{l}\text { Cathode } \\
\text { Number }\end{array}$ & 1 & 2 & 3 & 4 & 5 \\
\hline $\begin{array}{l}\text { Date } \\
\text { Installed }\end{array}$ & $6-1-1997$ & $10-4-1999$ & $9-28-2000$ & $3-6-2003$ & $6-6-2005$ \\
\hline $\begin{array}{l}\text { Cathode } \\
\text { Metal }\end{array}$ & $\mathrm{Cu}$ & $\mathrm{Cu}$ & $\mathrm{Cu}$ & $\mathrm{Mg}$ & $\mathrm{Cu}$ \\
\hline $\begin{array}{l}\text { Crystal } \\
\text { Orientation }\end{array}$ & $\begin{array}{l}\text { Poly- } \\
\text { crystalline }\end{array}$ & $\begin{array}{l}\text { Poly- } \\
\text { crystalline }\end{array}$ & 100 & $\begin{array}{l}\text { Poly- } \\
\text { crystalline }\end{array}$ & $\begin{array}{l}\text { Poly- } \\
\text { crystalline }\end{array}$ \\
\hline $\begin{array}{l}\text { Cathode } \\
\text { Joint }\end{array}$ & none & none & Brazed & $\begin{array}{l}\text { Friction } \\
\text { Welded }\end{array}$ & none \\
\hline $\begin{array}{l}\text { Polishing } \\
\text { Technique }\end{array}$ & $\begin{array}{l}\text { Diamond } \\
\text { Paste }\end{array}$ & $\begin{array}{l}\text { Electro- } \\
\text { polish }\end{array}$ & $\begin{array}{l}\text { Diamond } \\
\text { Paste }\end{array}$ & $\begin{array}{l}\text { Diamond } \\
\text { Turned }\end{array}$ & $\begin{array}{l}\text { Diamond } \\
\text { Turned }\end{array}$ \\
\hline $\begin{array}{l}\text { Installation } \\
\text { Environment }\end{array}$ & Air & Nitrogen & Nitrogen & Air & Nitrogen \\
\hline
\end{tabular}

\section{Field and Current Measurements}

The current exiting the gun is measured with a remotely insertable Faraday cup. The Faraday cup used at the GTF combines the function of Faraday cup and beam flag in one diagnostic. The flag is mounted normal to the incident electron beam and is composed of either YAG or SLAC phosphor. The emitted light and electrons continue in the forward direction approximately $20 \mathrm{~mm}$ and then strike an electrically isolated stainless steel Faraday cup mounted at $45^{\circ}$ incidence. The surface of the Faraday cup is highly polished to form a mirror surface. The light is reflected down through a vacuum window to a CCD camera outside the beam chamber and the electron beam is fully stopped in the $15 \mathrm{~mm}$ thick stainless steel block. A second identical Faraday cup $25 \mathrm{~cm}$ downstream of the first verifies that the beam is completely stopped. Secondary electrons emitted from the Faraday cup surface are collected on the upstream flag which is at the same potential as the Faraday cup. A wire from the Faraday cup leads to an electrical feedthrough followed by a $150 \mathrm{MHz}$ low-pass filter and an approximately 100' RG 223 cable to the control room. The signal is terminated in a Tektronix digital oscilloscope with $50 \Omega$ impedance and an internal $20 \mathrm{MHz}$ low-pass filter. The area of each pulse is recorded and the total charge computed as the signal area divided by the $50 \Omega$ load impedance. In addition the peak of the pulse divided by the $50 \Omega$ load is recorded as the peak macropulse current in order to plot the Fowler Nordheim curves shown later. 
A solenoid immediately downstream of the gun is used to optimize the electron beam collection onto the Faraday cup approximately $50 \mathrm{~cm}$ from the cathode. The dark current is measured as close to the cathode as possible to maximize the charge collection. The second Faraday cup collects roughly $50-70 \%$ of the charge measured on the first Faraday cup due to the poor beam quality of the dark current.

The field is recorded from the calibrated rf probes in both the full and half cell [1]. The capacitively coupled probe tips are recessed below the cavity surface and the response should be $<-50 \mathrm{~dB}$ to avoid damage to electronics downstream of the probe. We gradually degraded a medium power $(50 \mathrm{~W}$ average, $2 \mathrm{~kW}$ peak) attenuator with a $-46 \mathrm{~dB}$ probe response but have never damaged a probe. The ideal probe response is about $-53 \pm$ $2 \mathrm{~dB}$ in order to maximize the signal level without damaging equipment. In the history of the GTF we have never seen the cell to cell field ratio vary (field distribution change) once the tuning is complete. Although only a single probe is required, multiple probes to simultaneously measure the field in both cells at high power is desirable.

The measured forward, reflected and gun probe signals are shown in Figure 2. The time axis for each signal has not been corrected for cable length differences. The gun probe signals show less power than the forward power signal primarily due to the short rf pulse. The flat part of the forward power pulse is approximately $1.5 \mu$ s long but the gun filling time is $550 \mathrm{~ns}$ so the field never reaches steady state. The probe signals correspond to a peak on axis field of $120 \mathrm{MV} / \mathrm{m}$. The out-of-phase oscillations on the full and half cell probes are due to the 0 and $\pi$ modes beating at the mode-separation frequency of $3.5 \mathrm{MHz}$. This beating results in a large correlated energy spread at the gun exit [2] and was the motivation for increasing the mode separation to $15 \mathrm{MHz}$ in the LCLS gun.

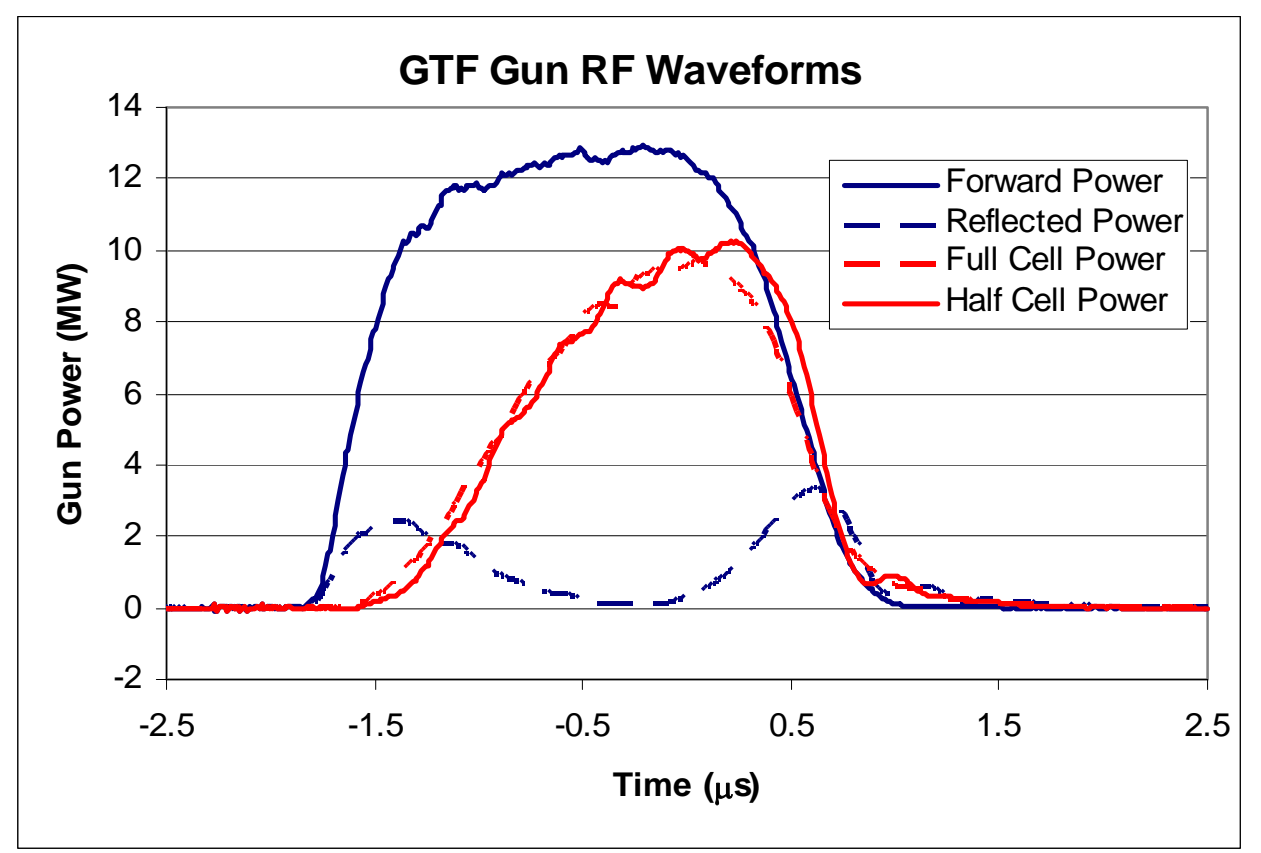

Figure 2 The typical forward and reflected rf power signals along with the rf probe signals vs time. 
The GTF gun has been processed by both varying the rf amplitude of the incident field and varying the incident field pulse length. Neither method appears significantly better than the other in terms of speed of processing or number of breakdown events. The field versus number of shots is shown in Figure 3 for cathodes 3-5. The number of shots required to reach the peak field is between 5 and 8 million shots. While processing we try not to generate more than approximately 1 breakdown per minute and the field is decreased if the breakdown rate exceeds that value. Figure 3 does not show every shot experienced by the cathode but rather only the shots while actively processing the gun. Most of the shots shown in the figure at fields below the peak field envelope are not due to breakdown but are data points where we are acquiring data for Fowler-Nordheim analysis described below. Additional 10's of millions of shots while operating the gun at fields below the peak field envelope are not shown in figure 3. Not all the rf processing was conducted sequentially as gun operation was intermixed with rf processing which was done periodically over the cathode lifetime.

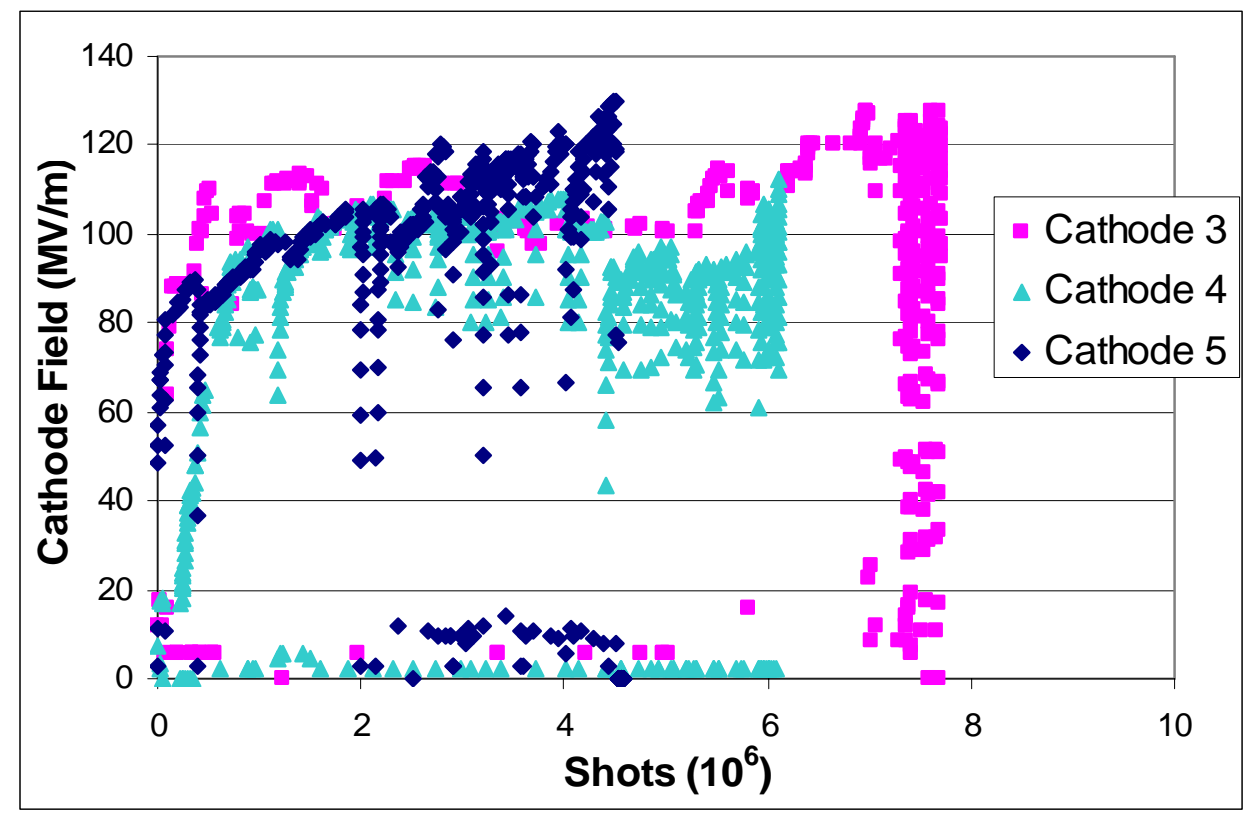

Figure 3 The peak field at the cathode versus number of shots for cathodes 3-5.

The dark current can vary significantly over time. Figure 4 shows the total dark charge per macropulse versus peak field at the cathode for cathodes 3-5. Each cathode is plotted separately to show the changes in dark current over time. Some breakdown events are accompanied by an increase in dark current, after which the increase is gradually processed away.

The maximum dark charge ever recorded at the GTF is over $4 \mathrm{nC}$ at $130 \mathrm{MV} / \mathrm{m}$. However a more typical charge is approximately $2 \mathrm{nC}$ at the same field. Of course no two cathodes respond identically and the charge does vary with time. Often the dark charge decreases with time as the cathode is continually being processed. 
Several images of the cathode 4 dark current captured on the 100 micron thick YAG beam flag are shown in Figure 5. The dark current typically has large energy spread due to the rf accelerating field which leads to the interesting curves on images downstream of the solenoid due to the cyclotron motion. The hot spot in the images appeared after a breakdown event that doubled the dark current. The increased dark current conditioned away after several days of processing, but the effect remained as a source of enhanced, non-uniform photo-emission. The hot spot is approximately $1.4 \mathrm{~mm}$ from the physical cathode center as determined by comparison with photo-emitted beam. Each image is 640 pixels wide by 480 pixels tall with $9.7 \mu \mathrm{m}$ per pixel.
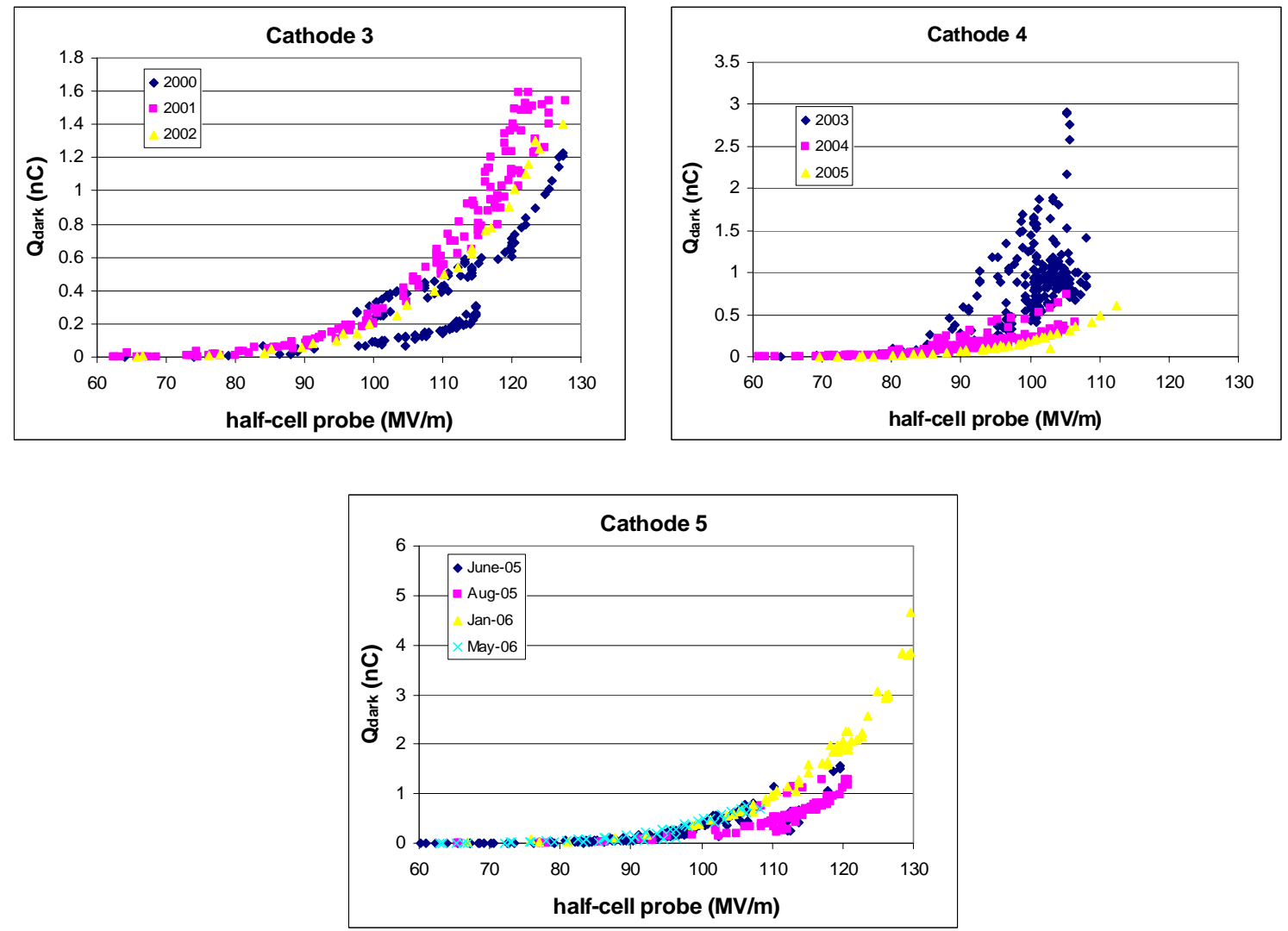

Figure 4 The dark charge is plotted as a function of peak field at the cathode for cathodes $3-5$. The charge variation with time is also shown. 

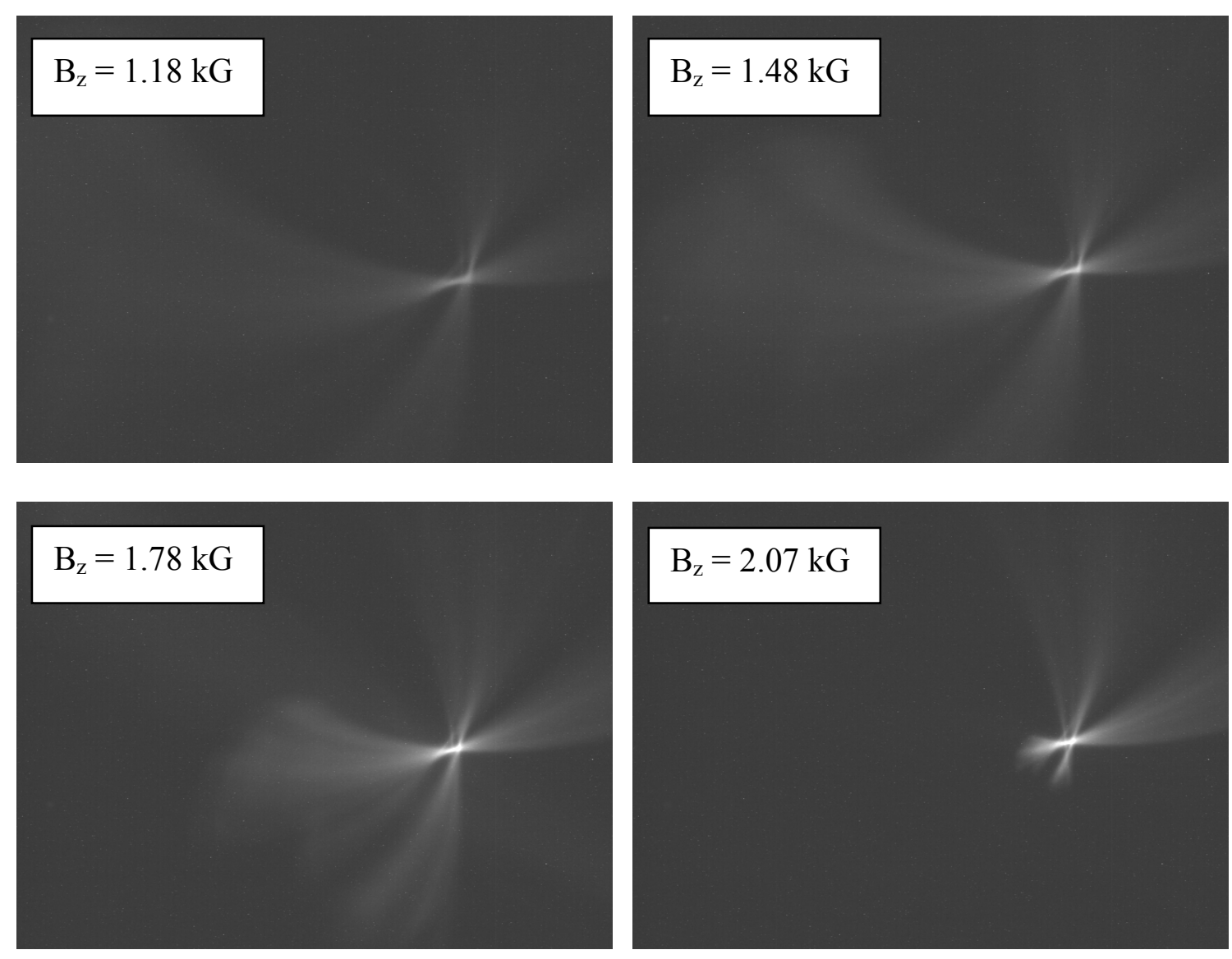

Figure 5 Images of the dark current on the beam flag at the different solenoid fields listed on the image are shown. Images obtained at $\approx 95 \mathrm{MV} / \mathrm{m}$ with cathode number 4 and roughly $300 \mathrm{pc}$ of total dark current.

The amount of dark current generated is highly dependent on the cathode surface in addition to the applied field. Field emitters are usually characterized using Fowler Nordheim analysis. The time averaged Fowler Nordheim [3] equation (averaged over an rf period) is shown in equation 1 where $\Phi$ is the work function $(4.65 \mathrm{eV}$ for $\mathrm{Cu}$ and $3.66 \mathrm{eV}$ for $\mathrm{Mg}$ ), $\mathrm{E}_{\mathrm{RF}}$ is the peak rf field and $\mathrm{I}_{\text {peak }}$ is the peak macropulse current. The parameters dependent on the cathode surface are the field enhancement factor $\beta_{\mathrm{FN}}$ and emitter area $A_{e}$. Equation 1 can be rewritten in the form of a line shown in equation 2 from which the slope and intercept can be used to compute these two parameters. Plots of equation 2 are shown in Figure 6 and the bottom right figure shows the evolution of the field enhancement factor as a function of measurement number. The time interval between each measurement varied but was typically 2-3 months. The magnesium cathode has a much lower field enhancement factor because $\mathrm{Mg}$ has an approximately $1 \mathrm{eV}$ lower work function than $\mathrm{Cu}$.

$$
I_{\text {peak }} \approx 5700 \frac{10^{4.52 \Phi^{-0.5}} A_{e}\left(\beta_{F N} E_{R F}\right)^{2.5}}{\Phi^{1.75}} e^{\frac{-6530 \Phi^{1.5}}{\beta_{F N} E_{R F}}}
$$




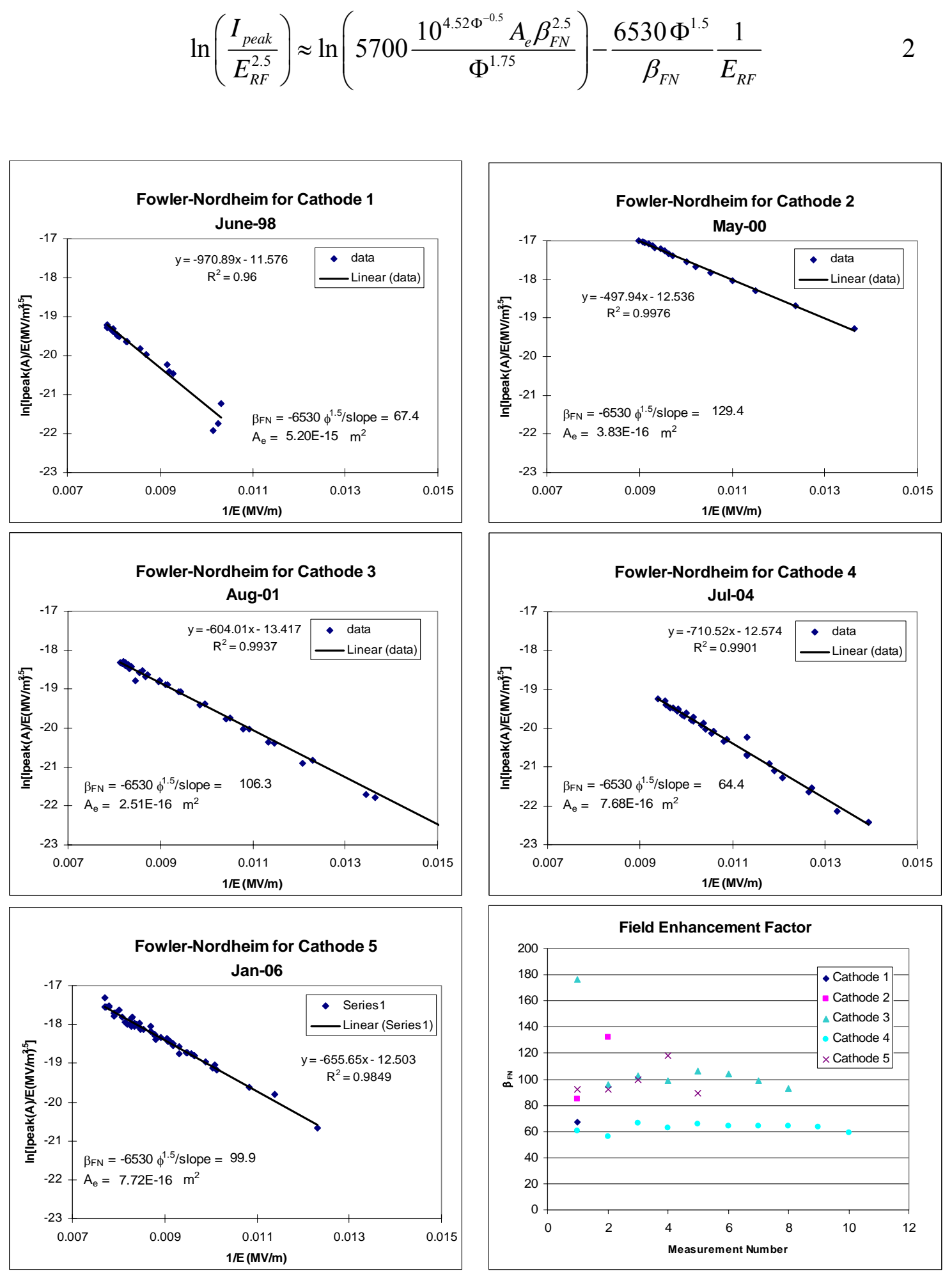

Figure 6 Typical Fowler Nordheim plots for all five GTF cathodes. The figure on the bottom right shows the variation of the field enhancement factor over time for each cathode. 
It would seem that the best method for generating a Fowler Nordheim curve would be to measure the field and current vs time over the macropulse instead of using just a single point of the curve. This is the method used to generate the data shown in Figure 7. The figure on the left is the measured field at the cathode and the emitted dark current vs time and the figure on the right is the resulting Fowler Nordheim curve. The data does not generate a straight line Fowler Nordheim curve like the data in Figure 6 and the field enhancement factor was significantly higher than reported above. The current vs time data has been delayed to compensate for cable length differences in an attempt to linearize the Fowler Nordheim data. Adding or subtracting delay between the two pulses did not produce a better result. This discrepancy is most likely due to different frequency responses of the rf probes and Faraday cup. We typically report Fowler Nordheim results using the peak current and field data like that shown in Figure 6 since it produces a better linear fit.
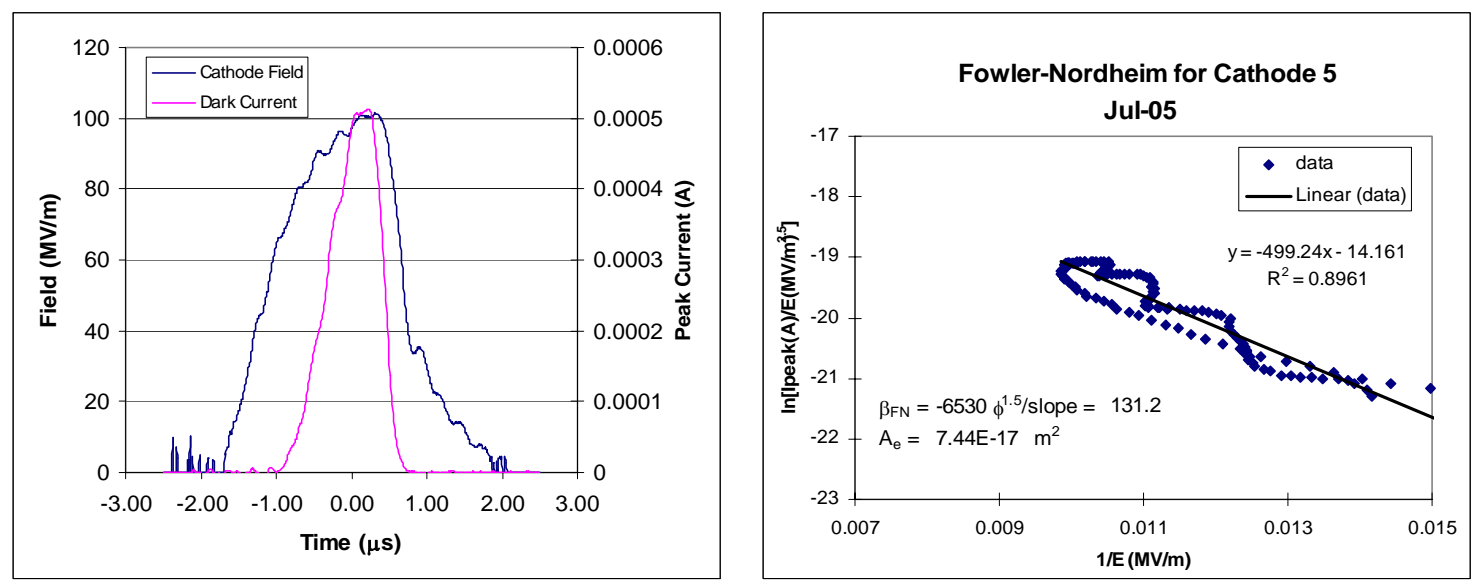

Figure 7 Current and field vs time on the left. The figure on the right is the Fowler Nordheim curve for this data.

\section{Breakdown}

We captured waveforms for the forward and reflected rf signals as well as the two gun probes and the dark current on a breakdown shot and compared them with a normal shot. The waveforms are plotted vs time in Figure 8. We are limited by available rf detectors to only record two simultaneous rf signals per shot so not all signals are available on each breakdown event.

Breakdown events are not always visible on the rf forward power pulse. However, they are clearly visible on the other rf signals but with different signatures. The reflected power shows a spike at the time of the arc presumably because the gun is shorted and the rf power is actually reflected. The half cell field always shows a dip while the full cell field shows a spike. There is no known reason for the field to actually increase due to the 
arc. Both the half cell and full cell probes have identical design but the breakdown causes one signal to increase and the other to decrease. This is likely providing a clue as to the location of the arc but that theory has not been pursued. Breakdown events do not always occur at the same point in time. Some breakdowns occur while the field in the gun is still increasing but nearly $75 \%$ occur after the peak of the pulse. All breakdown events produce a large number of electrons as measured on the Faraday cup and a toroid plus a bright flash is visible on the beam flag. Typically the vacuum pressure also spikes coincident with the breakdown and may cause a MPS trip if too many breakdowns occur. As mentioned earlier we try to minimize the number of breakdown events while processing by controlling the rf field amplitude. After a sufficient time with minimal breakdown events, the vacuum pressure decreases and the field can be raised.
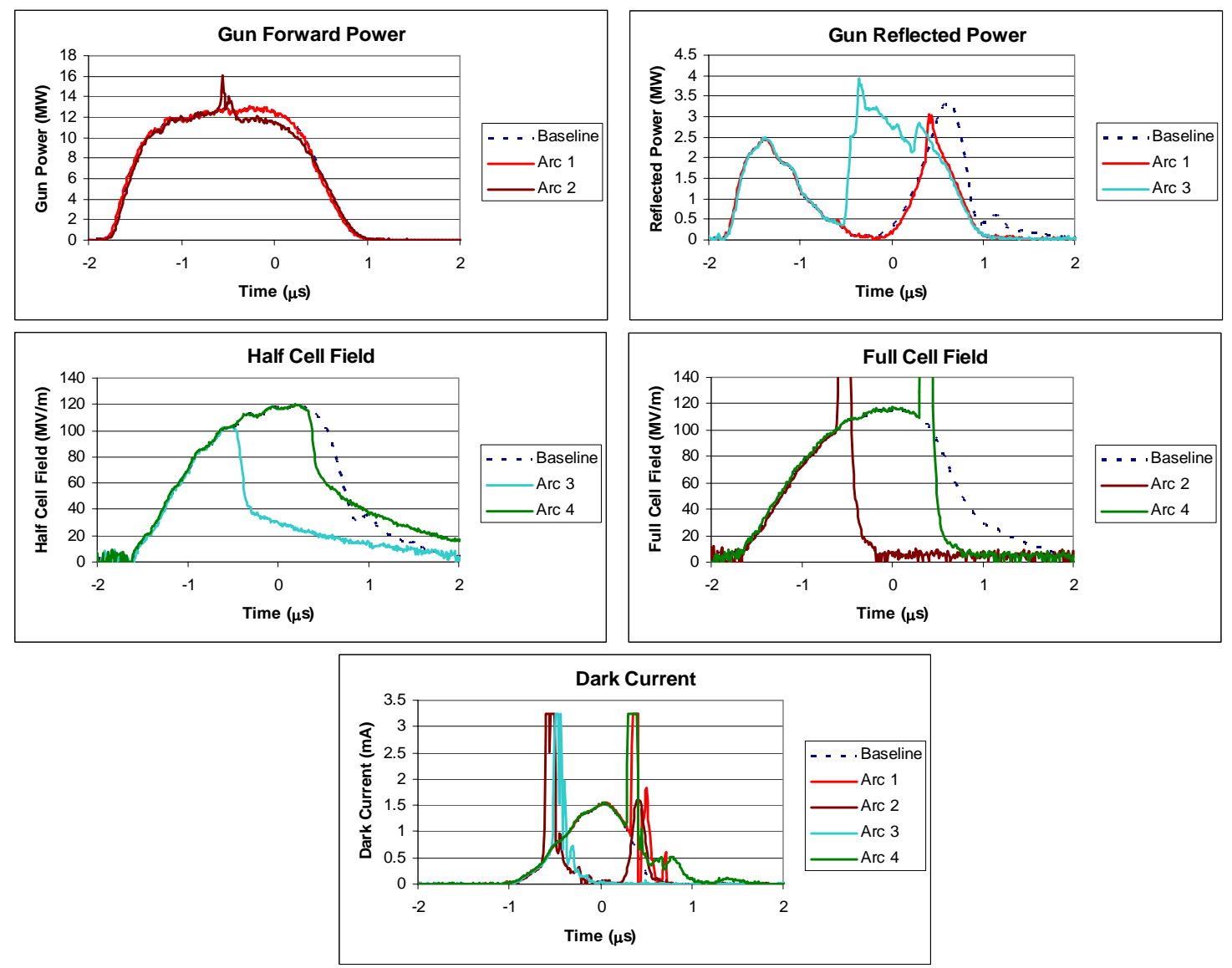

Figure 8 RF forward, reflected, half cell and full cell fields plus current as a function of time for a baseline shot with no breakdown and four shots with breakdown.

\section{Conclusions}

The rf processing experience with the GTF gun was presented. Peak rf field, total dark current, vacuum pressure and other signals must be recorded during rf processing. Processing to full field of approximately $120-130 \mathrm{MV} / \mathrm{m}$ requires approximately 8 million shots. The maximum dark current at this field should be $<4 \mathrm{nC}$ and is typically 
$<2 \mathrm{nC}$. We find the linearity of the Fowler Nordheim curve is best when measuring the peak current and peak field of the macropulse at different power levels as opposed to measuring the field and current vs time. The field enhancement factor for a $\mathrm{Cu}$ cathode is approximately 100. Breakdown events occur at different points in time along the pulse but always have the same signature for a given signal. At the GTF the full cell probe always show a field spike at the time of the arc although it is doubtful the field is actually increasing but may be related to the proximity of the detector to the breakdown. A large number of electrons are emitted during each breakdown which can damage diagnostics. Breakdown events also typically cause the dark current to increase on subsequent pulses. The dark current will slowly decrease shot to shot until the next breakdown. Breakdown is not visible on the rf forward power signal but is visible on nearly every other diagnostic including the vacuum pressure.

\section{Acknowledgements}

The authors would like to acknowledge discussions and the assistance of all the GTF operators, past and present. We also appreciate the assistance from the SSRL SPEAR operators and technicians. None of the work reported here would be possible without their labor.

\section{References}

[1] S.M. Gierman and J.F. Schmerge, LCLS-TN-06-15, 2006.

[2] J.F. Schmerge, J. Castro, J.E. Clendenin, D.H. Dowell, S.M. Gierman and H. Loos, SLAC-PUB-11702, 2006.

[3] J.W. Wang, SLAC Report 339, 1989. 